\title{
O enfoque Metodológico da História Oral na pesquisa em Serviço Social
}

\section{The Focus on Methodology of Oral History Research in Social Work}

\section{Reginaldo Guiraldelli}

\begin{abstract}
Resumo: Este ensaio, baseado em análise bibliográfica do tema, pretende apresentar alguns elementos sobre a apropriação da história oral como possibilidade metodológica na pesquisa em Serviço Social. A história oral, procedimento metodológico interdisciplinar presente nas Ciências Humanas e Sociais, se caracteriza essencialmente pelo recorte qualitativo, enfatizando as fontes, narrativas e relatos orais de sujeitos singulares e coletivos, sem perder de vista a análise histórico-crítica e a perspectiva de totalidade.
\end{abstract}

Palavras-chave: Serviço social. Pesquisa. História oral.

\begin{abstract}
This essay, based on literature review of the topic you want to display some elements on the appropriation of oral history as a possibility in methodological research in Social Work. Oral history, in this methodological procedure interdisciplinary humanities and social sciences, is essentially characterized by qualitative fragment, emphasizing sources, oral histories and narratives of collective and singular subjects, without losing sight of the historical-critical analysis and perspective of totality.
\end{abstract}

Keywords: Social work. Search. Oral history

*Doutor em Serviço Social pela Universidade Estadual Paulista “Júlio de Mesquita Filho" (Unesp). Professor Adjunto do Departamento de Serviço Social e do Programa de Pós-Graduação em Política Social da Universidade de Brasília (UnB). Coordena o Grupo de Estudos e Pesquisas sobre Trabalho, Sociabilidade e Serviço Social (GEPETSS/UnB). Brasília, Distrito Federal, Brasil. E-mail: reginaldog@unb.br 


\section{Introdução}

Nos últimos decênios, o Serviço Social tem apresentado um significativo salto qualitativo no seu acervo e na produção de conhecimentos envolvendo os diversos âmbitos da formação e do exercício profissional. Isso é notado diante da expansão na produção acadêmico-profissional, tanto nos trabalhos de conclusão de curso de graduação, nos mestrados, doutorados, especializações, aperfeiçoamentos, capacitações, quanto na produção e sistematização de conhecimentos oriundos da experiência, vivência e atuação nos diversos espaços ocupacionais. Esse quadro pode ser constatado nos últimos anos, quando se observa o aumento de apresentações de trabalhos na forma de relatos de experiência nos fóruns, congressos e encontros organizados pela categoria profissional. A socialização das experiências profissionais, com seus dilemas, repercussões, impasses, desafios, limites, possibilidades e sua respectiva publicização traz inúmeras contribuições para os assistentes sociais refletirem criticamente sobre a realidade social em que se revelam as múltiplas manifestações da questão social, compreendida como objeto de investigação e intervenção do Serviço Social e resultado das contradições, antagonismos e desigualdades produzidas no capitalismo.

Nesse sentido, é importante sublinhar que ao pensar na pesquisa em Serviço Social não se deve estabelecer sobreposição das formas de conhecimento, priorizando o que é produzido no âmbito acadêmico da universidade e menosprezando a produção das experiências cotidianas que circundam o exercício profissional, pois o conhecimento possui diferenças de natureza e não de hierarquia. Por isso, é preciso destacar que não se faz pesquisa somente no espaço da universidade. A pesquisa é competência e atribuição do assistente social e, por isso, está presente no cotidiano do exercício profissional.

A pesquisa pode e deve ser realizada cotidianamente nos espaços ocupacionais em que se inserem os assistentes sociais, pois o profissional, para atuar de forma crítica, competente, qualificada, propositiva, tendo como horizonte os princípios norteadores do projeto ético-político, necessita do conhecimento teórico-metodológi$\mathrm{co}$, e isso requer postura investigativa. Ou seja, para o profissional assegurar um princípio ético fundamental que norteia sua atuação, como por exemplo, prestar um serviço de qualidade à população, necessita compreender a estrutura e a conjuntura societária do tempo presente e isso prevê, como pré-requisito, pesquisa sistemática, incessante, profunda e crítica.

Essa prerrogativa exige do assistente social o conhecimento dos fundamentos da sociabilidade burguesa e as particularidades da formação sócio-histórica mundial, nacional, estadual, municipal e/ou local. Para isso, o profissional necessita se aproximar de conhecimentos produzidos por outras áreas, como a economia política, a história, a sociologia, a ciência política, a antropologia, dentre outras. A partir dessa base, acúmulo e mergulho profundo nos fundamentos que interpretam e analisam o significado da vida social, o assistente social se apropria de habilidades e competências técnico-operativas objetivando responder às demandas postas e necessidades sociais com vistas aos fins que orientam o projeto ético-político da profissão. Nesse aspecto, o assistente social precisa ter clareza das finalidades da sua atuação profissional para buscar os meios correspondentes.

Em se tratando de pesquisa e produção de conhecimento no âmbito do Serviço Social, também é relevante apontar os avanços apresentados na profissão a partir dos anos 1980 , que Netto (2001), no contexto do Movimento de Reconceituação, denominou de intenção de ruptura. Esse período é marcado pela aproximação à tradição marxista e ruptura com o tradicional conservadorismo, baseado nos preceitos do pragmatismo, do tecnicismo, do metodologismo, do desenvolvimentismo, do neotomismo e do positivismo.

Porém, diante de uma apreensão dialética desse processo, destacamos que esse movimento não ocorreu de forma mecânica e programática, ou seja, a Teoria Social de Marx não substituiu o conservadorismo no Serviço Social imediata, esquemática e bruscamente. Pelo contrário, concepções e abordagens conservadoras permanecem vivas e (re)atualizadas na atualidade. O que ocorreu foi que a tradição marxista ganha fôlego e torna-se um campo fecundo de análise no âmbito do Serviço Social a partir dos anos 1980, sobretudo após o III Congresso Brasileiro de Assistentes Sociais de 1979, mais conhecido como Congresso da Virada, em que o

122 Emancipação, Ponta Grossa, 13, nEspecial: 121-131, 2013. Disponível em <http://www.revistas2.uepg.br/index.php/emancipacao 
Serviço Social passa a demarcar sua posição e sua direção social e política, dando novos rumos para a formação e o exercício profissional. Isso se verifica com a revisão curricular no ano de 1982, seguida pela de 1996, a revisão do código de ética em 1986, e, em seguida, a de 1993, e também a Lei de Regulamentação da Profissão de 1993. Esses instrumentos, diretrizes e princípios, tornaram-se os elementos constitutivos e balizadores do projeto ético-político da profissão, considerado hegemônico no âmbito da categoria.

Outro dado importante é o surgimento da pós-graduação (mestrado) em Serviço Social em 1972 e, posteriormente, o doutorado, em 1981, que ao longo dessas décadas tem contribuído na estimulação de pesquisas e produção de um conhecimento crítico e comprometido com a classe trabalhadora.

Assim, com o surgimento dos mestrados e doutorados na área de Serviço Social, a profissão amadureceu intelectualmente. Atualmente é reconhecida como área de produção de conhecimento pelos diversos órgãos de fomento à pesquisa, como a CAPES, o CNPq e as fundações de amparo à pesquisa dos estados brasileiros, tendo em vista as expressivas contribuições dos profissionais para os múltiplos ramos do saber.

Diante disso, a concepção de um assistente social meramente técnico, prático, interventivo e executor de políticas sociais tem sido descontruída a partir de um esforço coletivo da categoria profissional em produzir conhecimentos de suma relevância para o Serviço Social e para as diversas áreas do conhecimento.

O que se observa é um processo de maturação do Serviço Social nas últimas décadas, tendo produzido um acervo bibliográfico diversificado sobre assuntos inerentes à área de interesse dos assistentes sociais e demais profissionais que atuam diretamente com as múltiplas refrações da questão social.

Posto isso, se verifica que determinados temas são mais recorrentes nas pesquisas realizadas pelos assistentes sociais, talvez pela maior incidência e necessidade da sua compreensão nos espaços da formação e do exercício profissional, como é o caso das políticas sociais, em especial com enfoque na seguridade social, abrangendo a saúde, previdência e assistência social. Além desses, outros temas como relações de trabalho, violência, educação, formação pro- fissional, movimentos sociais, gênero, desigualdades sociais, dentre outros, têm sido assuntos recorrentes na pauta de debates da categoria.

Mas como a realidade é dinâmica, contraditória e complexa, esses estudos e pesquisas de maior incidência no Serviço Social serão sempre necessários e relevantes, visto que são inesgotáveis e sempre assumem novas configurações de acordo com a conjuntura de uma época, tendo em vista que a questão social se manifesta de diversas formas no decurso histórico mediante as prerrogativas e ordenamentos do capitalismo e o grau de acirramento da luta de classes.

Também é importante considerar que certos temas ainda são incipientes e pouco problematizados no debate profissional, como é o caso da apropriação metodológica da história oral na pesquisa em Serviço Social. Como ponto de partida desse debate é importante diferenciar método e metodologia, para não se incorrer em equívocos e distorções. Método é entendido como a capacidade de apreensão do movimento contraditório da realidade social em uma perspectiva de totalidade, com base em análises concretas de situações concretas. Já a metodologia diz respeito aos procedimentos utilizados no percurso investigativo à luz de um método de análise. Tanto no método quanto na metodologia não há neutralidade, pois a escolha do método e da metodologia prevê uma intencionalidade.

Sabendo da aproximação e identificação do Serviço Social com a tradição marxista, consubstanciada no projeto ético-político profissional, no momento de incorporação da história oral como recurso metodológico na produção de conhecimento também é possível partir de uma perspectiva dialética, histórica e crítica, estabelecendo mediações e reconhecendo as conexões do singular com o universal que se dão no campo da particularidade, como pontua Pontes (2009).

Com isso, pensar a pesquisa na formação e no exercício profissional possibilita ao assistente social apreender o campo da singularidade (o fato isolado, a imediaticidade, o aparente) de forma crítica, questionadora e reflexiva, sintonizando-a com a universalidade, tendo como parâmetro a totalidade complexa da vida social e as mediações necessárias. No campo da universalidade, de acordo com Pontes (2009), 
se compreende as leis tendenciais da sociedade, identificando as relações entre Estado e sociedade, o tensionamento entre capital e trabalho, as relações sociais capitalistas, dentre outras complexidades. O campo das mediações, ou seja, a particularidade, conforme apresentado por Pontes (2009), é o momento em que o singular se universaliza e o universal se singulariza.

Por isso, é fundamental ao assistente social a negação do aparente, do efêmero e da imediaticidade como "verdades dadas e inquestionáveis", de forma a buscar a essência dos fatos, fenômenos e processos sociais, pois conhecendo criticamente a estrutura, dinâmica e complexidade do real é possível superar fatalismos, moralismos, messianismos, voluntarismos e culpabilizações. A partir disso, torna-se possível projetar alternativas profissionais e societárias sintonizadas por um compromisso coletivo.

A história oral pode ser um dos recursos possíveis para se realizar essas construções, sabendo que o conhecimento sempre se constitui por aproximações sucessivas, pois a realidade é inesgotável, diante da sua complexidade e dinamicidade.

Fazer a relação do singular e universal é uma tarefa que exige dos assistentes sociais fundamentação teórica, metodológica, ética, política e técnica para compreenderem as mediações nos espaços ocupacionais junto às demandas profissionais e institucionais. Isso implica também extrapolar o cotidiano como espaço da reificação, da aparência, da imediaticidade, ou seja, do real caótico, como observa Pontes (2009).

A partir desse entendimento, se faz imprescindível o desenvolvimento de pesquisas como forma de aprofundar os conhecimentos acerca da questão social e assim garantir uma intervenção qualificada na realidade concreta. Portanto, pensar a intervenção pressupõe pensar a investigação. Isso significa que investigação e intervenção possuem uma relação dialética de unidade.

Da mesma forma que não há dicotomia entre teoria e prática, não há dicotomia entre investigação e intervenção e entre saber e fazer profissional. Incorre-se em armadilhas ao se sustentar o discurso restrito do "fazer profissional", pois na ausência do saber, o profissional pode reproduzir uma atuação pautada restritamente na dimensão técnico-operativa, ou seja, no fazer prático e instrumental, ausente de suporte teóri$\mathrm{co}$, metodológico, ético e político.

Assim, com vistas a enfatizar a metodologia da história oral como uma das possibilidades (por isso não única e exclusiva) na produção de conhecimentos no Serviço Social, que dialoga aportes teóricos com a realidade, concebe-se e vislumbra-se um recurso investigativo de pesquisa que não recusa análises referenciadas no movimento histórico e numa perspectiva de totalidade. Essa metodologia também não despreza ou inferioriza as singularidades dos sujeitos (individuais e coletivos) que vivenciam a miséria, as degradantes condições de vida e trabalho, a discriminação, o preconceito, a violência, dentre outras durezas, mazelas e contradições presentes na sociabilidade capitalista. Por isso, cabe apresentar algumas abordagens sobre a metodologia da história oral como forma de aproximação ao debate.

\section{História oral: concepções e abordagens}

A história oral, compreendida como um procedimento metodológico interdisciplinar, ou seja, como um caminho para a construção de conhecimento, que abarca tanto uma dimensão teórico-política quanto uma dimensão técnica, tem tido, nas últimas décadas, uma expansão significativa no Brasil. De acordo com Meihy e Holanda (2007, p.64), a "História oral é um processo de registro de experiências que se organizam em projetos que visam a formular um entendimento de determinada situação destacada na vivência social". 1

O recurso à metodologia da história oral como um dos procedimentos possíveis de análise crítica e interpretação da realidade social se alicerça na busca de qualidade e profundidade investigativa com os sujeitos sociais envolvidos no processo de construção do conhecimento.

\footnotetext{
1 "A moderna história oral nasceu em 1948, na Universidade de Colúmbia, em Nova York. Allan Nevins, então, organizou um arquivo e oficializou o termo, que passou a ser indicativo de uma nova postura em face da formulação e da difusão das entrevistas. Isso se deu quando se combinaram os avanços tecnológicos com a necessidade de se propor formas de captação de experiências como as vividas então, tanto por combatentes como por familiares e vítimas dos conflitos da Segunda Guerra Mundial" (MEIHY, 2002, p.89).
} 
Conforme argumentação de Meihy e Holanda,

História oral é um conjunto de procedimentos que se inicia com a elaboração de um projeto e que continua com o estabelecimento de um grupo de pessoas a serem entrevistadas. O projeto prevê: planejamento da condução das gravações com definições de locais, tempo de duração e demais fatores ambientais; transcrição e estabelecimento de textos; conferência do produto escrito; autorização para o uso; arquivamento e, sempre que possível, a publicação dos resultados que devem, em primeiro lugar, voltar ao grupo que gerou as entrevistas. (2007, p.15).

Os autores acrescentam que o principal fundamento da história oral se constitui em uma dimensão social que abarca a memória coletiva e a identidade social (MEIHY; HOLANDA, 2007, p.131) e, nessa linha de raciocínio, Delgado (2006, p.9) ressalta que "[...] a memória é uma construção sobre o passado, atualizada e renovada no tempo presente". A autora afirma que a memória engloba tanto as dimensões individuais quanto coletivas e traz as marcas da lembrança e do passado.

Portanto, a memória passa a se constituir como fundamento de processos identitários, referindo-se a culturas, comportamentos e hábitos coletivos, uma vez que o relembrar individual - especialmente aquele orientado por uma perspectiva histórica - relaciona-se à inserção social e também histórica de cada depoente. (DELGADO, 2006, p.46).

Sendo assim, os indivíduos sociais, partícipes de pesquisas e produções de conhecimento, no tempo e no espaço, reconstituem, pelo crivo da memória, o seu ser e estar no mundo como indivíduos situados e representantes de uma coletividade, perpassada pela questão identitária de classe, que transita entre o reconhecimento de similitudes, diferenças e desigualdades.

Delgado argumenta que,

[...] as identidades podem ser renováveis e, na maior parte das vezes, encontram-se demarcadas pelo reconhecimento e pela constatação das diferenças. As identidades são representações coletivas contextualizadas e relativas a povos, comunidades, pessoas, já que a humanidade não é genérica nem caracterizada por universalismo abstrato
[...] Não há identidade sem alteridade, sem comparação. (2006, p.61).

Nesse entendimento, se observa que o ser social é singular e genérico, membro de uma coletividade e de uma classe social em que compartilha experiências, crendices, valores, ideologias, projetos, dentre outras aspirações, pois "o ser humano tem múltiplas raízes: familiares, étnicas, regionais, nacionais, religiosas, partidárias, ideológicas, culturais. Sua vida é uma totalidade, na qual processos diversificados conformam a dinâmica do viver." (DELGADO, 2006, p.51).

Baseadas nessa perspectiva, Ferreira e Amado (2006) afirmam que, a partir da introdução de abordagens sobre memória, identidade e subjetividade, em especial após a década de 1980 , a produção científica passou a valorizar a pesquisa qualitativa e, assim, deu importância às experiências e percepções dos indivíduos sociais, tendo em vista que as narrativas singulares podem transmitir uma experiência coletiva e representar uma concepção de mundo/sociedade.

Assim advém a contribuição da história oral na produção do conhecimento, que se caracteriza, entre as várias possibilidades teóricometodológicas de análise dos indivíduos sociais, por uma especial atenção aos segmentos de classe silenciados e subalternizados socialmente, priorizando suas raízes, seu cotidiano, o espaço da vida privada, as inserções na vida pública, os projetos individuais e coletivos, as territorialidades e, desse modo, "[...] procura destacar e centrar sua análise na visão e versão que dimanam do interior e do mais profundo da experiência dos atores sociais." (LOZANO, 2006, p.16).

Além disso, o autor pontua que "fazer história oral significa, [...], produzir conhecimentos históricos, científicos, e não simplesmente fazer um relato ordenado da vida e da experiência dos 'outros'." (LOZANO, 2006, p.17).

Nesse sentido, pode-se compreender a história oral como um procedimento metodológico que, conforme apresentado por Janotti (1996, p.60), rompe as barreiras do silêncio e do anonimato advindos da vida cotidiana, enfatizando acontecimentos, experiências e percepções que não se encontram registradas na documentação escrita e tampouco nas versões oficiais da historiografia.

Com base nessa concepção de história oral, é importante destacar sua preocupação com 
o alcance social da pesquisa e a forma como os resultados retornarão aos sujeitos partícipes da construção do conhecimento. Cabe considerar o compromisso desse procedimento metodológico em estabelecer vínculos com os participantes/ sujeitos da pesquisa para que possam construir um diálogo democrático, respeitoso e fraterno na busca de compreensão das diversas situações concretas vivenciadas pela sociedade.

Mas, vale recordar que nem sempre tal metodologia teve adesão no espaço acadêmico-científico, pois apenas assumiu destaque na atualidade, uma vez que até a primeira metade do século XX a produção acadêmica e científica se respaldava em documentos escritos e em experimentos comprovados, pois a fonte oral não possuía critério de validade e de confiabilidade. Diante desse cenário, a narrativa oral era rejeitada como produto do conhecimento científico e representava falibilidade aos critérios objetivos e racionais de cientificidade.

Com o passar do tempo, diante de revisões e questionamentos das concepções determinísticas, normativas e quantificáveis da produção acadêmica, predominantes até o início da segunda metade do século $X X$, verificouse uma mudança de concepção e postura na apropriação do conhecimento e foi possível reconhecer nos estudos nas áreas das ciências humanas e sociais a dimensão ontológica da vida social, considerando as condições objetivas e subjetivas da sociabilidade humana. A partir desse movimento, as fontes orais também passam a ser reconhecidas como elementos relevantes na produção do conhecimento. Com isso, a história oral ganha terreno e reconhecimento nas Ciências Humanas e Sociais como uma forma alternativa de se propor análises acerca da realidade social.

A partir disso, a história oral foi sendo gradativamente incorporada por algumas áreas do conhecimento, com o intuito de decifração da realidade social e busca de respostas aproximadas às diversas questões e situações oriundas do avanço técnico-científico. Dentre as áreas com expressiva adesão aos procedimentos metodológicos da história oral, destacam-se a História, a Sociologia, a Antropologia, a Psicologia, a Linguística, a Comunicação e, atualmente, o Serviço Social.
O Serviço Social, profissão inserida na divisão sócio-técnica do trabalho como uma especialização do trabalho coletivo (IAMAMOTO, 2003) e reconhecida como área de conhecimento, conjugando em sua formação e exercício profissional a dimensão interventiva e investigativa, tem em sua organização basilar um projeto ético-político com orientações e formulações teórico-metodológicas direcionadas para a defesa de uma Teoria Social Crítica, com base na tradição marxista.

Nesse sentido, cabe sublinhar que a história oral não recusa uma determinada direção social. Sendo uma abordagem metodológica e, por isso mesmo isenta de neutralidade, pode se nortear (ou não) por compromissos políticos com os sujeitos sociais e se respaldar (ou não) em preceitos teóricos embasados na tradição marxista. Pesquisas baseadas na metodologia da história oral também podem se apropriar de outras abordagens e concepções analíticas. Por isso, esse ainda é um debate recente e importante para ser aprofundado no âmbito das Ciências Humanas e Sociais.

Diante disso, cabe considerar que a apropriação metodológica da história oral a partir da apreensão da tradição marxista, permite o desvelamento das complexidades e contradições do real em suas múltiplas determinações, a fim de extrapolar o fragmento, o reducionismo, a imediaticidade e volatilização dos fatos, fenômenos e processos. Nessa perspectiva, a história oral, como recurso metodológico na produção de conhecimento, pode contribuir dialeticamente para a ultrapassagem do mundo da aparência, retratado por Kosik (1989) como mundo da pseudoconcreticidade, para desvendar a essencialidade contraditória e dinâmica dos processos sociais.

\section{Serviço Social e História Oral: uma aproximação}

Apropriar-se da história oral como procedimento metodológico na pesquisa em Serviço Social requer enfatizar as fontes orais e as narrativas como elementos norteadores na análise da realidade e das relações sociais. A história oral, compreendida como metodologia de pesquisa e campo interdisciplinar de encontro de diferentes áreas do saber, [...] não é um fim em si mesma, e sim um meio de conhecimento." (ALBERTI, 2005, 
p.29). Sendo assim, a história oral não recusa e nem substitui a pesquisa acadêmica com seu rigor científico e tampouco a documentação oficial existente. Pelo contrário, a história oral contribui e fornece subsídios qualitativos para a produção de conhecimento por meio das fontes orais.

Por isso, a partir das histórias narradas pelos sujeitos partícipes de um processo investigativo, podem ser traçados inúmeros elementos que circundam as relações sociais, sejam as experiências individuais e coletivas, as trajetórias, tradições, relações familiares, os aspectos econômicos, políticos, sociais, culturais, religiosos, o território, a rede de sociabilidade, pois esses são elementos que tecem a vida em sociedade. Contudo, é importante salientar que as histórias narradas são sempre recortadas, mediante a referência do tempo presente da narrativa. Assim, se reconhece a importância de apreensão das relações sociais sob o prisma da totalidade e do movimento histórico, de forma a não fragmentar a realidade.

A história oral, como metodologia, tem como base as narrativas orais dos sujeitos que relatam suas experiências, valores, crendices, fatos, projetos, aspirações e acontecimentos da vida privada e pública e, com isso,

Através da narrativa de uma história de vida, se delineiam as relações com os membros de seu grupo, de sua profissão, de sua camada social, da sociedade global, que cabe ao pesquisador desvendar. Há histórias de vida mais ou menos ricas, mais completas ou mais fragmentadas. (LANG, 1996, p.34). ${ }^{2}$

Para apreender a riqueza das histórias narradas, um dos instrumentos utilizados na pesquisa é a entrevista.

A técnica da entrevista é incorporada pela história oral como processo dialógico e como instrumento de registro de experiências individuais e/ou coletivas, que objetiva capturar expressões do real pela via da documentação oral, ou seja, da linguagem verbalizada pelos sujeitos partícipes do conhecimento produzido. Sendo assim,

A documentação oral quando apreendida por meio de gravações eletrônicas feitas com o propósito de registro torna-se fonte oral. A his-

${ }^{2}$ Em sua obra, Meihy (2002) identifica três perspectivas da história oral: a história oral de vida, a história oral temática e a tradição oral. tória oral é uma parte do conjunto de fontes orais e sua manifestação mais conhecida é a entrevista. (MEIHY; HOLANDA, 2007, p.14).

As pesquisas que adotam os procedimentos metodológicos da história oral se respaldam na apreensão de uma realidade situada, com suas circunstâncias, temporalidades, determinações históricas, e com sujeitos vivos, pois "o espaço e o tempo da história oral, [...], são o 'aqui' e o 'agora', e o produto é um documento." (MEIHY; HOLANDA, 2007, p.15).

Ademais, "A evidência oral, transformando os 'objetos' de estudo em 'sujeitos', contribui para uma história que não só é mais rica, mais viva e mais comovente, mas também mais verdadeira." (THOMPSON, 2002, p.137, grifo do autor).

Conforme Lang (1996, p.36),

É no indivíduo que a História Oral encontra sua fonte de dados, mas sua referência não se esgota nele, dado que aponta para a sociedade. O indivíduo que conta sua história, ou dá seu relato de vida não constitui ele próprio o objeto de estudo; a narrativa constitui a matéria prima para o conhecimento sociológico que busca, através do indivíduo e da realidade por ele vivida, apreender as relações sociais em que se insere em sua dinâmica.

A autora acrescenta que "A versão do indivíduo tem, portanto, um conteúdo marcado pelo coletivo" (LANG, 1996, p.45) e também conforme Meihy (2002, p.68), "[...] a história oral é sempre social. Social, sobretudo porque o indivíduo só se explica na vida comunitária".

Portanto, metodologias pautadas na história oral têm sido adotadas e centradas em estudos que abordam sujeitos silenciados e subalternizados ao longo da história e, por isso, em sua maioria, enfatizam mulheres, negros, homossexuais, migrantes, quilombolas, indígenas, dentre outros segmentos da classe trabalhadora. ${ }^{3}$

Além do mais, a pesquisa com as experiências e trajetórias dos sujeitos possibilita a compreensão de ser e estar no mundo no plano da singularidade e também sua relação com

\footnotetext{
3 “[...] a esquerda e os militantes têm sempre estado atentos à 'voz proletária' ou dos subalternos para poder usá-la como argumento da transformação social. A íntima relação com aqueles que não detém o código escrito é uma das marcas mais fortes da história oral" (MEIHY, 2002, p.96)
} 
os processos sociais, econômicos, culturais e políticos em sua universalidade.

Considerando esse cenário, a história oral se torna um arcabouço para a apreensão da realidade, que é de suma importância para o Serviço Social, tendo em vista que essa profissão e área de conhecimento têm como uma de suas preocupações as experiências e histórias de vida da população demandatária dos serviços prestados pelos profissionais. Assim, se busca no cotidiano de trabalho do assistente social compreender a realidade e a temporalidade em que os sujeitos estão situados. Pela aproximação das histórias de vida é possível articular experiências concretas e cotidianas dos indivíduos sociais com questões genéricas que envolvem as relações humanas e, assim, compreender as multifaces da questão social ${ }^{4}$.

O campo investigativo e interventivo do Serviço Social se circunscreve nas manifestações da questão social e nos seus desdobramentos na cena contemporânea. Nesse prisma, o Serviço Social tem adotado uma perspectiva de problematizar e considerar algumas discussões, tais como o mundo do trabalho, as relações de gênero, os direitos humanos, a violência, as desigualdades, dentre outros assuntos que tangenciam a questão social. O debate acerca dessas temáticas contribui para a reflexão teórica, a realização de pesquisas, o posicionamento ético-político e a qualificação do trabalho profissional.

Por isso, os assistentes sociais devem se empenhar em compreender as dimensões singulares e universais do real, a partir das experiências e vivências da população que demanda seus serviços, para apreenderem as relações contraditórias e conflitantes entre capital e trabaIho no cerne de uma realidade complexa, palco da luta de classes.

Nesse aspecto, pensar a pesquisa e a produção do conhecimento nas Ciências Humanas e Sociais e, considerando as especificidades do Serviço Social, exige uma aproximação aos sujei-

\footnotetext{
${ }^{4}$ Com base nas obras de lamamoto (2003; 2008), a questão social é resultante das desigualdades sociais, expressas na contradição capital versus trabalho, no momento em que, tendo como cenário o século XIX, os trabalhadores passam a reivindicar direitos e sua legitimidade de classe, fazendo pressão junto ao bloco dominante representado pelo Estado e burguesia.
}

tos sociais sem desconsiderar e/ou descaracterizar os processos políticos, culturais, sociais, simbólicos, ideológicos e econômicos, pois somente assim torna-se exequível construir possibilidades de ação. Por isso, para não cair em falsas abstrações, é imprescindível atribuir historicidade aos processos sociais, ou seja, partir do devir histórico das relações sociais, compreendendo o real como síntese de múltiplas determinações, permeadas de rupturas e continuidades.

O que pode ser destacado é que, ao longo do seu processo de maturação intelectual, o Serviço Social tem contribuído de forma significativa para a produção do conhecimento nas áreas das Ciências Sociais e Humanas. Nesse sentido, tem buscado estratégias de enfrentamento das refrações da questão social a partir de uma fundamentação teórica, ética, política e metodológica consistente, diante do incentivo de pesquisas na área e pelo vínculo orgânico entre investigação e intervenção.

Uma das características peculiares na produção do conhecimento em Serviço Social é a centralidade do trabalho, tendo como referência a perspectiva sócio-histórica, os sujeitos e suas relações sociais. A atuação profissional dos assistentes sociais possui como epicentro as ações direcionadas ao atendimento das refrações da questão social, que se expressam nas histórias de vida da população usuária dos serviços prestados pelas instituições nas quais o profissional está inserido como trabalhador assalariado.

Assim, é importante considerar que os sujeitos que constituem o público atendido pelos profissionais de Serviço Social são dotados de valores, experiências, singularidades, sentimentos, sonhos, projetos e expectativas e, por isso, há a necessidade de conhecê-los, buscando desvelar o sentido que essa população atribui para sua realidade, sua vida, sua história e seu contexto.

Por isso, se torna indispensável o conhecimento pelos profissionais dos diversos aspectos que agudizam as manifestações da questão social e que circundam a vida da população, seja no trabalho, nas relações familiares, nas organizações sociais e políticas, nas expressões culturais, na ausência de direitos, nas carências socioeconômicas, na segregação territorial, no desmonte das políticas públicas, dentre outros elementos que perpassam a história da humanidade e são reflexos da sociabilidade burguesa, 
que se sustenta na desigualdade social entre classes antagônicas.

Sendo assim, uma das contribuições da pesquisa para a área de Serviço Social é trazer à tona experiências e histórias de vida de sujeitos individuais e coletivos, como forma de se aproximar da realidade e, assim, possibilitar ações críticas, criativas e propositivas que atendam aos interesses efetivos da população.

Para tanto, a profissão tem se apropriado de aportes teórico-metodológicos para decifrar a realidade social, utilizando de abordagens quantitativas e qualitativas para a apreensão da questão social.

A dimensão qualitativa ganhou terreno nos últimos decênios nas Ciências Humanas e Sociais, tendo em vista seu foco de abordagem direcionado para as relações sociais. $\mathrm{Na}$ abordagem qualitativa,

[...] a realidade do sujeito é conhecida a partir dos significados que por ele the são atribuídos. Esse é fundamentalmente o motivo pelo qual se privilegia a narrativa oral. Não se trata, portanto, de uma pesquisa com um grande número de sujeitos, pois é preciso aprofundar o conhecimento em relação àquele sujeito com o qual estamos dialogando. [...] No que se refere às pesquisas qualitativas, é indispensável ter presente que, muito mais do que descrever um objeto, buscam conhecer trajetórias de vida, experiências sociais dos sujeitos [...] (MARTINELLI, 1999, p.23-25).

É importante mencionar que a pesquisa qualitativa também considera a totalidade da vida social e sua abordagem não significa o menosprezo pela dimensão quantitativa. Afinal, os dados quantitativos e estatísticos contribuem para o processo de construção do conhecimento. Sendo assim, conforme apresenta Minayo (2000), as pesquisas qualitativas e quantitativas possuem natureza de complementaridade e não de oposição.

A pesquisa baseada na história oral enfatiza a dimensão qualitativa, pois lida com histórias, experiências e trajetórias de sujeitos singulares e coletivos. Por isso, parte da compreensão de seus relatos, depoimentos e narrativas para a compreensão e leitura crítica da realidade social. Mesmo considerando a pesquisa quantitativa como um elemento também necessário na produ- ção do conhecimento, a metodologia da história oral não tem como prioridade enfatizar esse tipo de abordagem, porém, não o recusa como um aporte para o aperfeiçoamento das pesquisas.

O Serviço Social, por atuar diretamente com sujeitos concretos, historicamente situados, dotados de valores, sentimentos, sonhos, projetos, ações, não recusa a pesquisa quantitativa, mas, pelo contrário, reconhece sua importância e contribuição para a análise da realidade. Porém, a profissão também tem como primazia em suas pesquisas a abordagem qualitativa, por buscar compreender a trama das relações sociais capitalistas, objetivando respostas aproximativas às satisfações e necessidades humanas. Sendo assim, a apropriação da história oral na pesquisa em Serviço Social é relevante por contribuir diretamente com o propósito investigativo e interventivo da profissão no que tange à decifração das múltiplas manifestações da questão social na contemporaneidade.

\section{Conclusão}

O Serviço Social, nas últimas décadas, tem se consolidado como uma profissão investigativa e interventiva, pois busca, por meio do conhecimento acumulado e sistematizado, apreender os fundamentos da questão social no sentido de contribuir com respostas às situações e necessidades concretas das demandas da população.

Em sua gênese, o Serviço Social brasileiro incorporou conhecimentos oriundos da doutrina social da Igreja, do pragmatismo, e sofreu fortes influências do lastro positivista até o início da segunda metade do século $X X$.

Somente em meados dos anos 1960 é que a profissão passou a repensar suas bases teóricas, metodológicas, ideológicas e políticas, originando o Movimento de Reconceituação latino-americano da profissão que trouxe inúmeros avanços para a categoria profissional. A partir desse Movimento, também denominado por Netto (2001) de Renovação, a profissão se aproxima de outras matrizes teórico-metodológicas, como é o caso da tradição marxista e da fenomenologia. Mas somente nos anos 1980 é que o Serviço Social rompe com suas bases tradicionais e inaugura uma fase direcionada para a compreensão dialética da realidade, com respaldo na Teoria Social de Marx. 
A partir dessa apropriação teóricometodológica pelo Serviço Social e diante das exigências atuais de enfrentamento da questão social em suas múltiplas dimensões é que emerge a necessidade da interlocução da profissão com a história oral, visando conhecer de forma aproximativa as condições de vida e trabalho dos indivíduos sociais que recorrem aos profissionais buscando respostas às situações vivenciadas.

A grande preocupação para que os assistentes sociais se apropriem desse procedimento metodológico de forma consistente, fundamentada e comprometida com os preceitos do projeto ético-político profissional é não desconsiderar no processo investigativo elementos basais como a objetividade, a subjetividade, a singularidade, a totalidade, a historicidade e as contradições presentes na vida social.

Frente ao explicitado, é importante ressaltar que o intuito da metodologia da história oral não é buscar "verdades" absolutas e estanques, mas apresentar e revelar as experiências e percepções dos sujeitos sociais com base em suas narrativas para uma maior aproximação com a realidade circunscrita.

A história oral tem como centralidade a contribuição do indivíduo social na construção do conhecimento, valorizando substancialmente sua essência, ou seja, sua subjetividade, experiências, visão de mundo e impressões sobre a realidade. Mesmo sendo indivíduos isolados, que narram suas histórias singulares, são também representantes de um coletivo e de uma classe social. Por isso, por mais que os depoimentos sejam individuais, eles refletem uma experiência e uma história coletiva.

A apropriação da história oral, em muitos casos, acontece, conforme mencionado por Meihy (2002, p.24), quando não há vestígio documental, ou estes se apresentam em variações distintas da história oficial ou mesmo quando se pretende elaborar outra versão da história.

Quando a cultura oficial aborda os grupos excluídos, colocando-os como tema de seus estudos, o faz por via indireta, pelos documentos escritos. Assim, essas análises são sempre "sobre" eles e nunca "deles". (MEIHY, 2002, p.31).
Diante do exposto, trazer as narrativas e histórias de vida dos indivíduos sociais para a cena contemporânea torna-se um grande desafio no que tange ao processo de produção do conhecimento e pesquisa, pois, de acordo com Thompson,

Aprender a ouvir é uma habilidade humana fundamental: para aqueles que importam, a história oral está aí para nos ajudar a compreender melhor nossos passados e para criar memórias nacionais muito mais ricas, mas também para nos ajudar a construir um futuro melhor, mais amável, mais democrático. (2002, p.28).

Com isso, se apropriar da história oral requer de pesquisadores e profissionais de diversas áreas o desafio de conhecer o passado para entender o presente e forjar o futuro. Para isso, é crucial a produção de conhecimentos, tanto para avançar no acúmulo e amadurecimento teórico, metodológico, ético e político, quanto para fundamentar e qualificar o exercício profissional em busca de novas sínteses que apreendam o movimento contraditório do real e contribuam efetivamente para a construção de uma sociedade emancipada.

Ao enfatizar a necessidade dos aspectos críticos, reflexivos, investigativos e interventivos na formação e exercício profissional do assistente social, inúmeros desafios se apresentam ao Serviço Social. E, para isso, é necessário considerar que esse movimento de divisas, de rupturas, tensionamentos e de inquietudes requer posturas densas, rigorosas, políticas e eticamente comprometidas com o conhecimento produzido no sentido da socialização, publicização e função social da pesquisa.

As reflexões e inquietações apresentadas acerca da história oral como possibilidade metodológica na pesquisa em Serviço Social e áreas afins não objetivam hierarquizar a produção de conhecimento, priorizando o acervo teórico e documental existente ou enfatizando relatos dos sujeitos sociais, mas reconhecer a importância, tanto do aporte teórico-documental, quanto das narrativas dos sujeitos singulares e coletivos para a compreensão da realidade social. 


\section{Referências}

ALBERTI, Verena. Manual de história oral. 3.ed. Rio de Janeiro: Ed. FGV, 2005.

BAPTISTA, Myrian Veras. A investigação em Serviço Social. São Paulo: Veras, 2006.

DELGADO, Lucilia de A. N. História oral: memória, tempo, identidades. Belo Horizonte: Autêntica, 2006.

FERNANDES, Maria Esther. A "história de vida" como instrumento de captação da realidade social. Cadernos CERU - Centro de Estudos Rurais e Urbanos, São Paulo, n.6, p.145-155, 1995.

FERREIRA, Amauri C.; GROSSI, Yonne de S. A narrativa na trama da subjetividade: perspectivas e desafios. Revista da Associação Brasileira de História Oral, São Paulo, n.7, p.41-59, 2004.

FERREIRA, Marieta Moraes. Desafios e dilemas da história oral nos anos 90: o caso do Brasil. Revista da Associação Brasileira de História Oral, São Paulo, n.1, p.19-30, 1998.

; AMADO, Janaína (Org.). Usos e abusos da história oral. 8.ed. Rio de Janeiro: Ed. FGV, 2006.

IAMAMOTO, Marilda V. O Serviço Social na contemporaneidade: trabalho e formação profissional. 6.ed. São Paulo: Cortez, 2003.

Serviço Social em tempo de capital fetiche: capital financeiro, trabalho e questão social. 3.ed. São Paulo: Cortez, 2008.

JANOTTI, Maria de Lourdes Mônaco. Refletindo sobre história oral: procedimentos e possibilidades. In: MEIHY, José Carlos Sebe Bom (Org.). (Re) introduzindo história oral no Brasil. São Paulo: Xamã, 1996.

KOSIK, Karel. Dialética do concreto. Rio de Janeiro: Paz e Terra, 1989.

LANG, Alice Beatriz da Silva Gordo. História oral: muitas dúvidas, poucas certezas e uma proposta. In: MEIHY, José Carlos Sebe Bom (Org.). (Re) introduzindo história oral no Brasil. São Paulo: Xamã, 1996.

LOZANO, Jorge Eduardo Aceves. Prática e estilos de pesquisa na história oral contemporânea. In: FERREIRA, Marieta de Moraes; AMADO, Janaína (Org.). Usos e abusos da história oral. 8.ed. Rio de Janeiro: Ed. FGV, 2006.

MARTINELLI, Maria Lúcia (Org.). Pesquisa qualitativa: um instigante desafio. São Paulo: Veras, 1999.
MEIHY, José Carlos Sebe Bom; HOLANDA, Fabíola. História oral: como fazer, como pensar. São Paulo: Contexto, 2007.

Loyola, 2002.

Manual de história oral. 4.ed. São Paulo:

(Org.). (Re) introduzindo história oral no Brasil. São Paulo: Xamã, 1996.

MINAYO, Maria Cecília de Souza (Org.). Pesquisa social: teoria, método e criatividade. 18.ed. Petrópolis: Vozes, 2000.

NETTO, José Paulo. Ditadura e Serviço Social: uma análise do Serviço Social no Brasil pós 64. 5.ed. São Paulo: Cortez, 2001.

PONTES, Reinaldo Nobre. Mediação e Serviço Social: um estudo preliminar sobre a categoria teórica e sua apropriação pelo Serviço Social. $6^{a}$ ed. São Paulo: Cortez, 2009.

SETUBAL, Aglair Alencar. Pesquisa em Serviço Social: utopia e realidade. 3.ed. São Paulo: Cortez, 2005.

THOMPSON, Paul. A voz do passado: história oral. 3.ed. Rio de Janeiro: Paz e Terra, 2002. 